\title{
Note
}

\section{CONSUMER TESTING OF COMMERCIAL MEDIUM GRAIN RICE VARIETIES ${ }^{\prime}$}

\author{
Fernando Pérez $z^{2}$, Carol Harper ${ }^{3}$, Karla Deza $a^{4}$ and Van H. Ayers ${ }^{5}$
}

J. Agric. Univ. P.R. 93(3-4):277-279 (2009)

A joint effort between the University of Missouri and the University of Puerto Rico at Mayagüez was part of a study conducted by a group of Mississippi Delta Region (Missouri) farmers. The objective of the study was to determine whether the quality of medium grain rice produced by Missouri farmers measured up to that demanded by Puerto Rico consumers.

Several sensory tests took place at various locations in Puerto Rico in order for us to get a better understanding of those quality attributes highly regarded by consumers. Results of those tests (Deza and Harper, 2005 ${ }^{6}$; Harper and Linhardt, 2005) ${ }^{7}$ suggested that no significant differences existed in terms of consumer preference among the various local brands and locations tested. One of said brands was the Missouri-grown variety. Therefore, the authors wanted to test the Missouri-grown variety against that from the Sacramento Valley Region (California).

According to a report by Boriss (2006), the Mississippi Delta region has the largest total area of rice production, but Sacramento Valley has the highest yields. These two areas, together with the Gulf Coast region, basically cover United States rice production. Boriss (2006) also states that $90 \%$ of the Sacramento Valley production is medium grain rice and that it accounts for about two-thirds of the United States medium grain market.

Given the dominant role of California-grown rice in the medium grain market, the authors saw the importance of determining how the Missouri variety measured up to that of California. In order to answer said question, the authors performed a consumer test with only two samples.

A total of 102 rice consumers participated in a paired preference test (Mielgaard et al., 2006). Varieties tested included CalRose Diamond G extra fancy white rice (California variety) and a Missouri variety commercial brand locally available under the Goya

${ }^{1}$ Manuscript submitted to Editorial Board 22 February 2008.

${ }^{2}$ Assistant Professor, Agricultural and Biosystems Engineering Department, University of Puerto Rico-Mayagüez Campus.

${ }^{3}$ Professor, Agricultural and Biosystems Engineering Department, University of Puerto Rico-Mayagüez Campus.

${ }^{4}$ Former Food Science and Technology Graduate Student, University of Puerto RicoMayagüez Campus.

${ }^{5}$ Agriculture and Rural Development Specialist, Agricultural Extension Service, University of Missouri.

${ }^{6}$ Deza, K and C. Harper, 2005. Consumer Test Rice Project. University of Puerto Rico. College of Agricultural Sciences. Unpublished report.

${ }^{7}$ Harper, C. and R. Linhardt, 2005. Consumer Test of medium grain rice in Puerto Rico. University of Puerto Rico. College of Agricultural Sciences. Unpublished report. 
TABLE 1. Consumer preferences by age group, gender and consumption frequency.

\begin{tabular}{lrr}
\hline & Missouri & California \\
\hline Preference by age group & & \\
15 to 25 years & 16 & 19 \\
16 to 45 years & 5 & 11 \\
46 to 55 years & 6 & 8 \\
Above 55 years & 12 & 14 \\
Unknown & 4 & 7 \\
Preference by gender & & \\
Female & 21 & 28 \\
Male & 18 & 22 \\
Unknown & 4 & 9 \\
Preference by consumption frequency & & \\
Occasionally & 4 & 4 \\
1 or 2 times per week & 7 & 11 \\
4 or 5 times per week & 13 & 15 \\
Daily & 14 & 20 \\
Unknown & 5 & 9 \\
\hline
\end{tabular}

Foods ${ }^{8}$ label. The same recipe (i.e, 2 cups of rice, $2 \frac{1}{1} 2$ cups of water, $1 / 2$ tsp salt, 4 tbsp cooking oil) was used to prepare the two varieties of rice in commercial rice cookers.

The sensory panel tasting took place at a supermarket located in Mayagüez, Puerto Rico. Supermarket shoppers who were rice consumers acted as test panelists. After giving some demographic data, each panelist received coded samples (one tablespoon) of each treatment in respective plastic cups. Each panelist was asked to evaluate the samples and to state his/her sample preference.

Analysis of data is based on a "successes" count and on the comparison of that value with the expected average of a binomial distribution. Success is taken as the greater number of panelists who preferred one particular sample over the other. For this experiment, fiftynine panelists preferred the California variety whereas forty-three preferred the Missouri variety. Thus, the number of successes is taken as 59. Demographic information was graphed to ensure that the sampled population was not biased toward a particular group.

All data considered, the expected average of a binomial distribution with 102 panelists is 51 (102 panelists/ two treatments). Comparing these values using the normal approximation of the binomial distribution and student $\mathrm{t}$ statistic, we found that no significant difference exists between the two varieties at the $95 \%$ confidence interval.

A paired comparison preference test was conducted between California and Missouri medium grain rice varieties. Fifty-nine out of 102 panelists preferred the California variety over the Missouri rice. Results gathered were insufficient evidence to discard the assumption of no difference among brands at the $95 \%$ confidence level.

${ }^{8}$ Company and trade names in this publication are used only to provide specific information. Mention of a company or trade name does not constitute a warranty of equipment or materials by the Agricultural Experiment Station of the University of Puerto Rico, nor is this mention a statement of preference over other equipment or materials. 


\section{LITERATURE CITED}

Boriss, H., 2006. Commodity Profile: Rice. Agricultural Issues Center. University of California. (http/aic.ucdavis.edu/profiles/Rice-2006.pdf)

Mielgaard, M., G. V. Civille and B. T. Carr, 2006. Sensory evaluation techniques. Fourth edition. CRS Press. 